\title{
A LEGITIMIDADE DO MINISTÉRIO PÚBLICO NA TUTELA DOS INTERESSES LIGADOS A EMBRIÕES CONGELADOS.
}

\section{THE LEGITIMATE PROSECUTOR IN PROTECTION OF INTEREST RELATED TO FROZEN EMBRYOS.}

\author{
Stela Queiroz dos Santos ${ }^{1}$ \\ Zaiden Geraige Neto ${ }^{2}$
}

\begin{abstract}
RESUMO: O presente artigo estuda a possibilidade de o Ministério Público intervir em casos relacionados à bioética e principalmente dentro da bioética, aos embriões congelados. $O$ trabalho demonstra esta possibilidade, a partir do direito à vida e sob o prisma da proteção do princípio da dignidade da pessoa humana e da Declaração de Helsinque, que é um documento de princípios éticos que visa fornecer orientações aos médicos e outros participantes de pesquisas clínicas envolvendo seres humanos. Examina a possibilidade de utilização de embriões para fins científicos, além de verificar o uso do banco de tumores para fins científicos e terapêuticos. Analisa a importância de o Ministério Público atuar como representante da sociedade e até mesmo de um particular eventualmente, pois é ele o protetor da coletividade e fiscal do cumprimento do ordenamento jurídico, ante a relevância e complexidade do tema, tendo em vista as inúmeras lacunas existentes em nossa legislação, buscando responder ao final se haverá tal possibilidade.
\end{abstract}

\footnotetext{
${ }^{1}$ Mestranda em Direitos Coletivos e Cidadania pela Universidade de Ribeirão Preto/SP UNAERP. Graduada em Direito pelo Centro Universitário da Fundação Educacional de Barretos/SP. Advogada. stelaqueiroz@adv.oabsp.org.br. Telefones: (16) 3877-8985/ (17) 81009087. Endereço: Praça Odair de Oliveira, 105, AP. 31, Jardim Nova Aliança, CEP: 14.026-591, Ribeirão Preto/SP.

${ }^{2}$ Doutor e Mestre em Direito pela PUC/SP. Professor de Direito do Mestrado Universidade de Ribeirão Preto/SP - UNAERP. Professor convidado do curso presencial de pós-graduação "lato sensu" em Direito Processual Civil da Faculdade de Direito da USP - Ribeirão Preto (FDRP/USP). MBA Executivo pela FGV (Fundação Getúlio Vargas). Membro efetivo e Diretor de Relações Institucionais do IASP (Instituto dos Advogados de São Paulo). Membro efetivo do IAB (Instituto dos Advogados Brasileiros). Parecerista e consultor da revista do Conselho da Justiça Federal. Advogado. zgneto@uol.com.br. Telefones: (17) 3322-6699. Endereço: Avenida 19, 1073, Centro, CEP: 14780-300, Barretos/SP.
}

REVISTA DO DIREITO UNISC, SANTA CRUZ DO SUL No $39 \mid$ p. 43 - 66|JAN-JUL 2013 
PALAVRAS-CHAVE: Bioética, biodireito, interesses difusos, coletivos e individuais homogêneos, embriões congelados, Ministério Público.

ABSTRACT: This article explores the possibility that the prosecutor intervene in cases related to bioethics and especially within the bioethics, the frozen embryos. The paper demonstrates this possibility, from the right to life and from the perspective of protecting the principle of human dignity and the Declaration of Helsinki. Examines the possibility of using embryos for scientific purposes and to verify the use of tumor bank for scientific and therapeutic. Analyzes the importance of the prosecutor acting as a representative of society and even a particularly appropriate, since he is the protector of the community and fiscal compliance with the legal system, given the importance and complexity of the issue, considering the numerous gaps in our legislation, seeking to answer the end there is that possibility.

KEYWORDS: Bioethics, biolaw, interests, collective and homogeneous, frozen embryos, the Public Prosecutor.

\section{CONSIDERAÇÕES INICIAIS}

O presente artigo trata da possibilidade de o Ministério Público intervir em fatos relacionados a embriões congelados.

Em um primeiro momento será analisado o instituto da bioética, esclarecendo seu conceito e surgimento, passando-se a analisar o biodireito, especificando seu conceito e fazendo comparações entre ele e a bioética.

Em um segundo momento, passaremos à análise dos princípios relacionados à bioética, os conceituando e explicando cada qual com suas especificidades.

Em um terceiro momento, analisaremos o instituto dos direitos coletivos, explicando o que são, bem como diferenciando os interesses difusos, coletivos 
e individuais homogêneos. Passando-se à explicação dos institutos processuais da legitimidade das partes e do interesse processual.

Por fim, será verificada a possibilidade de o Ministério Público intervir ou não em casos relacionados a embriões congelados, pois pode se tratar de interesses individuais homogêneos ou tratar somente de interesse individual.

$\mathrm{O}$ artigo em estudo trata de um tema bastante atual e relevante, pois ainda há muitas lacunas em nossa legislação e precisamos obter respostas no sentido de solucionar os problemas advindos em nosso cotidiano.

\section{BIOÉTICA X BIODIREITO}

A Bioética é parte da ética, um ramo da filosofia, que estuda as questões referentes à vida humana.

O termo "Bioética" foi utilizado pela primeira vez, em 1971, pelo oncologista e biólogo Van Rensselder Potter, um norte- americano da Universidade de Wisconsin, em Madison, em uma obra de sua autoria chamada Bioethics: bridge to the future, em que ele considerava a bioética como a ciência da sobrevivência, em um sentido ecológico.

Porém, podemos observar que o termo foi empregado somente em 1971, mas a bioética já estava inserida em nosso contexto há algum tempo, conforme podemos verificar os acontecimentos existentes em algumas datas anteriores.

Em 1900, foi elaborado pelo Ministério da Saúde da Prússia, o primeiro documento que estabelecia as diretrizes éticas para experimentação em humanos, ou seja, o consentimento do paciente, bem como as explicações necessárias do pesquisador a respeito das consequências e complicações advindas da pesquisa. Contudo, tal documento não foi respeitado.

Em 1931, devido a não repercussão do documento elaborado em 1900 e o seu desrespeito, na Alemanha, foram elaboradas 14 diretrizes, além das já estipuladas em 1900, para maior respeito e responsabilidade na pesquisa em humanos. Este documento também não foi acatado, pois entre 1933 e 1945, 
durante a $2^{\text {a }}$ Guerra Mundial, foram cometidas diversas atrocidades contra os seres humanos.

Em 1947 surge o Código de Nuremberg. Em 1948 a Declaração Universal dos Direitos Humanos (ONU), e em 1964 a Declaração de Helsinque (Assembleia Médica Mundial), bem como suas posteriores versões nos anos seguintes.

Em 25 de abril de 1953, foi descoberta a estrutura do DNA, onde surgiram novas possibilidades de pesquisas e que vem avançando até os dias atuais.

Em maio de 1960, houve a revolução da vida feminina com a pílula anticoncepcional, possibilidade maior de liberdade para as mulheres e 0 surgimento de uma bioética feminista.

Em 1967 ocorreu o primeiro transplante de coração e em 1968 houve a definição do momento em que ocorre a morte cerebral.

Em 1978 ocorreu o nascimento do primeiro bebê de proveta, devolvendo esperança a muitos casais inférteis.

Em 1997 nasce a ovelha Dolly, o primeiro mamífero clonado por transferência nuclear, surgindo muitas discussões a respeito da clonagem humana. E em 2000, desenvolve-se o primeiro rascunho do Genoma Humano, com $97 \%$ da sequência.

Com isso, verificamos que a bioética está inserida em nossa história desde muito antes de seu conceito ser determinado.

Para Fermin Roland Schramm e Marlene Braz (2012),

\begin{abstract}
a Bioética é uma ética aplicada, chamada também de "ética prática", que visa "dar conta" dos conflitos e controvérsias morais implicados pelas práticas no âmbito das Ciências da Vida e da Saúde do ponto de vista de algum sistema de valores (chamado também de "ética").
\end{abstract}

Já para Giovanni Berlinguer (1993. p. 19), o termo "bioética se refere, frequentemente, aos problemas éticos derivados das descobertas e das aplicações das ciências biológicas".

Conforme leciona Hubert Lepargneur (1996, p. 138), 
a bioética é entendida como o estudo sistemático da conduta humana na área das ciências da vida e dos cuidados da saúde, na medida em que esta conduta é examinada à luz dos valores e princípios morais. Complementando que, a bioética é a resposta da ética aos novos casos e situações originadas da ciência no campo da saúde. Poderse-ia definir a bioética como a expressão crítica do nosso interesse em usar convenientemente os poderes da medicina para conseguir um atendimento eficaz dos problemas da vida, saúde e morte do ser humano.

Assim, a bioética está diretamente relacionada com o valor, a moral e a ética, pois a bioética deve preservar estas três qualidades, sendo elas indispensáveis para a preservação da dignidade, dos princípios e dos valores morais advindos da conduta humana.

Neste sentido, temos o valor como uma seleção, um propósito de vida, o que nos impulsiona a escolher e valorizar a escolha realizada, tornando-se esta, a base de nossas afrontas.

A moral se trata de valores que procedem a regras, sendo consideradas corretas por determinada sociedade.

Durkheim explica a moral como a "ciência dos costumes", tratando-se de algo nasceu antes mesmo da sociedade em si.

Compreensível a visão de Durkheim, pois a moral está conosco todo o tempo desde o nascimento, é algo que carregamos conscientemente dentro de nós teoricamente, ao contrário da ética que é algo mais palpável que a moral. Contudo, as duas se complementam na tentativa de criarem situações mais justas e humanas.

Por fim, a ética é um código que regulamenta determinadas pessoas, como por exemplo, médicos, advogados, etc.

Os códigos de ética representam a consolidação dos princípios éticos assumidos por uma sociedade. "Considerando, entretanto, que os princípios são mutáveis, temos que os códigos são habitualmente retrógrados com relação ao "pensar ético", recomendando-se consequentemente sua análise crítica e revisão periódica" (SEGRE; COHEN, p. 21-22).

As primeiras manifestações sobre ética se deram no século $V$, a. C., onde houve o nascimento da filosofia política e moral e o início da preocupação com a democracia e a organização social. 
Os sofistas constituíram um movimento intelectual na Grécia do século V, a. C., porém não se interessavam pelas questões relativas ao mundo, considerando-as banais e sem importância, preocupando-se, somente, com questões referentes ao homem nos espaços político e jurídico. Com isso, realizaram um conhecimento prático, incentivando o homem a ter participação na política e reunir condições de convencimento e argumentação, pois para os sofistas não há verdade, não há norma permanente, sendo tudo questão de arguição do sujeito.

Acredita-se que os primeiros a pensarem a respeito de questões éticas foram os sofistas e Sócrates.

Além dos sofistas, a ética obteve muito valor com Platão e Aristóteles, pois nas palavras de Miguel Carlos Mádero, "Sócrates, rompendo, então, com o pensamento mítico, e com apoio no princípio da racionalidade, o grande pensador procurou fixar o princípio ético da responsabilidade pessoal de cada indivíduo. Segundo ele, os homens, em geral, e os governantes, em particular, são sempre responsáveis pelos resultados de seus atos e omissões intencionais. Em resumo, Sócrates, apregoava a sabedoria, como critério de ação, a partir da liberdade de cada um, fundando sua proposta ética na fórmula "Vive conforme tuas ideias, vive conforme tua razão".

Em sua juventude adotou como lema para sua vida, a inscrição que figurava na fachada do templo de Apolo em Delfos: "Conhece-te a ti mesmo".

Para Sócrates não havia "ética relativa: ou é ética, ou não é ética" (MÁDERO, 2010. p. 382).

Aristóteles elaborou a obra Ética a Nicômaco, que se trata de anotações referentes às aulas dadas ao seu filho, sendo considerada uma obra-prima da filosofia moral.

Hume explicava que os homens são influenciados em suas ações pelas paixões, surgindo inexplicavelmente e influenciando em razão do sentimento.

Já Kant, retomou os estudos de Aristóteles em relação ao âmbito teórico, que se trata do estudo do caso que ocorre no mundo, relacionado somente com sua própria dinâmica e o âmbito prático, que são os casos que ocorrem pela vontade do ser humano, sem nenhuma influência. 
Deste modo, nas palavras de Miguel Carlos Mádero (2010. p. 385),

\begin{abstract}
a Ética é o estudo da Moral: estuda os princípios da conduta humana, pinçando princípios de todas as civilizações e que sejam bons para a convivência humana. Mas, evidentemente, ambas estão ligadas por laços muito estreitos. O diferencial é que a Ética tem por característica a generalidade, enquanto que a Moral está sempre ligada às especificidades de um caso concreto. Cuidam, pois, de investigar e buscar explicações sobre comportamentos humanos, cada uma dentro de um universo determinado. Logo, como a Ética compreende o todo, a Moral nela está inserida posto que é parte.
\end{abstract}

A bioética engloba além de seu conceito, a macrobioética e a microbioética. A macrobioética trata-se da preservação da vida humana através de questões ecológicas e a microbioética é a relação entre o paciente e 0 médico.

\title{
2.1 Princípios
}

Os princípios que guiam os caminhos da bioética e ainda, conduzem à experimentação em seres humanos, são quatro, sendo eles: princípio da autonomia, princípio da beneficência, princípio da não - maleficência e princípio da justiça.

Estes princípios surgiram entre 1974 e 1978, com o relatório de Belmont, onde devido às atrocidades ocorridas nesta época, foram identificados os princípios básicos que norteariam a pesquisa com seres humanos.

O princípio da autonomia delineia que o paciente deve ser tratado com autonomia, ou seja, sua vontade ou de seu representante deve prevalecer e ser respeitada pelo profissional que o acompanha, claro que em certa medida devido às crenças religiosas ou valores morais.

O princípio da beneficência, determina que o profissional de saúde deve fazer o bem sempre, evitando-se o mal. Atendendo o paciente e visando seu bem-estar sempre.

Salienta Aline Mignon de Almeida (2000) que o princípio da beneficência é a avaliação entre os benefícios e os riscos (atuais e potenciais, 
individuais e coletivos) objetivando-se, assim, elevar ao máximo os benefícios e enfraquecer os danos e riscos.

O princípio da não-maleficência é o desenvolvimento do princípio estudado anteriormente, da beneficência, pois atribui ao profissional de saúde a obrigação de não provocar nenhum dano ao paciente de forma propositada.

E por fim, o princípio da justiça designa que todos deverão ser tratados igualmente, havendo, pois, uma repartição dos riscos e dos benefícios.

Nesse sentido, Daury Cesar Fabriz (2003) analisa que no campo da bioética o princípio da justiça está relacionado com o princípio da beneficência, tendo em vista que os dois visam o bem para as pessoas.

Destarte, estes princípios devem servir à bioética como balizes para uma pesquisa mais ética e moral.

\subsection{Biodireito}

O Biodireito se trata de regras, princípios e leis esparsas que ajustam e regulamentam os estudos realizados pelas biociências e biotecnologias, atualmente muito utilizadas para a descoberta de novas técnicas e aprofundamento de conhecimentos empregados em favor ou desfavor da vida humana, garantindo-se, com isso, a manutenção do princípio da dignidade da pessoa humana intacto, frente a todas essas novas descobertas.

É inegável a indispensabilidade do direito para manter-se o equilíbrio entre essas novas tecnologias, que avançam cada vez mais rápido, para que não haja prejuízo das normas já consagradas por nosso sistema jurídico.

Conforme explica Jussara Suzi Assis Borges Nasser Ferreira (2012), temos dúvidas primeiramente do ramo do direito que o biodireito faz parte.

De plano surge a indagação se o biodireito é sub-ramo do direito público ou do direito privado? O enfrentamento da questão considera que o biodireito pode tutelar tanto interesses de ordem pública, como também de ordem particular, quando alcança o ser humano, em sua individualidade enquanto sujeito de direito. Em favor do interesse público estão todas as tutelas à vida, desde as contidas no texto constitucional até aquelas referidas em legislações específicas, v.g. da lei $n^{\circ} 8.974$, de 05 de janeiro de 1995, que regulamenta os incisos II e V do $\S 1^{\circ}$ do art. 225 da CF, que estabelece normas para o uso 
das técnicas de engenharia genética e liberação no meio ambiental de organismos geneticamente modificados e a resolução 1.358/92 do Conselho Federal de Medicina, que dispõe sobre normas éticas para a utilização das técnicas de reprodução assistida, bem como a lei no 9.434/97 que dispõe sobre transplante de órgãos, tecidos e partes do corpo humano, com fins terapêuticos.

Assim, é possível concluir que o biodireito se insere no âmbito do direito público e do direito particular ao mesmo tempo, alcançando interesses públicos e particulares.

\section{O VALOR DO EMBRIÃO COMO SER HUMANO}

O embrião congelado, apesar de para muitos não significar um ser humano ele o é, e como tal, merece que sua dignidade seja respeitada, pois qualquer atividade realizada no embrião congelado pode afetar este ser humano.

Ressalta Emmanuel Carneiro Leão (2012), que:

a célula tronco embrionária do homem já é sempre vida humana, mesmo antes de desenvolver todo o cabedal de humanização, de que é capaz. Deixada entregue a si mesma, sem nenhuma intervenção agressiva, seja de dentro, seja de fora, ela vai percorrer todo o curso da realização humana, crescendo, amadurecendo e morrendo em si, por si e para todos. Intervir destrutivamente numa célula tronco embrionária do homem já inclui sempre em qualquer fase de seu desenvolvimento uma agressão iníqua à vida humana na singularidade irrepetível de sua integração de ter e ser.

A questão decisiva não é, pois, se a célula em causa é ou não viável, mas se é ou não humana, destinada pela criação, a gerar vida humana. Ser e não ser viável é sempre uma possibilidade concretamente dada a todo ser mortal. Todavia da mortalidade não vale concluir a permissão de matar, para qualquer fim que seja. É que há uma diferença radical e irredutível na condição humana e para a condição humana entre a possibilidade de morrer e permissão para matar. É justamente porque o homem é mortal e está sempre sob a lei da morte que tem sentido e se impõe o mandamento: "não matarás".

Com essa compreensão, é fácil perceber que devemos preservar o emprego ontológico do embrião, pois é uma vida que deve percorrer todo o caminho de ser "humano". 
O direito deve estar atento a todas as questões que sejam relacionadas ao envolvimento de embriões congelados a qualquer tipo de pesquisa, tipo de descarte, entre outros, pois é uma vida humana que está sendo manuseada, devendo possuir valor absoluto.

Sarlet (2004) pondera a respeito da dignidade individual pertencente a cada ser.

(...) a dignidade, na condição de valor intrínseco da pessoa humana, evidentemente não poderá ser sacrificada, já que, em si mesma, insubstituível (...). No mínimo - e neste sentido já não se poderá falar de um princípio absoluto - impende reconhecer que mesmo prevalecendo em face de todos os demais princípios (e regras) do ordenamento, não há como afastar - como ainda teremos oportunidade de discutir - a necessária relativização (ou, se preferimos, convivência harmônica) do princípio da dignidade da pessoa em homenagem à igual dignidade de todos os seres humanos.

(...) a própria dignidade individual acaba, ao menos de acordo com o que admite parte da doutrina constitucional contemporânea, por admitir certa relativização, desde que justificada pela necessidade de proteção da dignidade de terceiros, especialmente quando se trata de resguardar a dignidade de todos os integrantes de determinada comunidade.

Entende-se, deste modo, que deve ser reconhecida a relativização em alguns casos, bem como a tolerância de algumas práticas. Contudo, é inconcebível que atos atentatórios à dignidade do ser individual, enquanto embrião congelado sejam permitidos, pois conforme dito anteriormente, este embrião é um ser humano possuindo grande valor ontológico.

\section{DIREITOS COLETIVOS}

Os interesses coletivos foram marcados inicialmente pela tentativa inglesa, com o sistema da common law, em que se originou a possibilidade de tutela de interesses coletivos, com a criação de instrumentos capazes de proporcionar tal fenômeno.

Conforme Teori Albino Zavascki (2007, p. 28) citando Vincenzo Vigoriti, explica que 
desde o século XVII, os tribunais de equidade (Courts of Chancery) admitiam, no direito inglês, o bill of peace, um modelo de demanda que rompia com o princípio segundo o qual todos os sujeitos interessados devem, necessariamente, participar do processo, com o que se passou a permitir, já então, que representantes de determinados grupos de indivíduos atuassem, em nome próprio, demandando por interesses dos representados ou, também, sendo demandados por conta dos mesmos interesses.

Com isto, surgiu a ação de classe, conhecida por class action. Entretanto, a aplicação e o progresso desta ação foi lento até o século XIX, pois em 1873, com o surgimento do Court of Judicature Act, a ação de classe ganhou um sentido mais vivo, se tornando mais atualizada e bastante difundida a partir de 1938, se formando em algo original e novo.

Nos países da civil law, a partir dos anos 70 do século $X X$, a preocupação era a de aprimorar os modelos existentes de institutos processuais, com a intenção de aperfeiçoa-los para que se tornem aptos à defesa dos interesses coletivos.

Já nos países da Europa, não houve a grandeza das class action, que existiu nos países norte-americanos, apesar disso, ocorreu uma experiência em 1973, com a Loi Royer, em que se estabelecia em seu artigo 46 que as associações que estivessem regularmente declaradas tendo por objeto estatutário a defesa de consumidores, poderiam proceder à defesa do interesse coletivo dos consumidores, atuando quando autorizadas.

Na Espanha, de acordo com a Ley General para La Defensa de lós Consumidores y Usuarios, ocorreu algo bastante parecido, pois esta atribuiu legitimidade ativa às associações, para proposição de demandas coletivas em questões relativas ao consumo e em seguida, a Ley Organica Del Poder Judicial, em 1985, atribui não só às associações a legitimidade ativa, como também às corporações e grupos atingidos ou que estejam legalmente habilitados para a sua defesa.

Na Itália, por influência do Tratado da União Europeia de 1992, foi criada a Lei n. 281 de 1998, em que foi reconhecida a possibilidade de tutela de direitos coletivos relativa aos consumidores.

$\mathrm{Na}$ Alemanha, foi também acolhida a tutela de interesses coletivos relativa aos consumidores e ao meio ambiente por associações.

REVISTA DO DIREITO UNISC, SANTA CRUZ DO SUL No $39 \mid$ p. 43 - 66| JAN-JUL 2013 
Por fim, em Portugal foi visualizado um grande progresso, tendo em vista ser o procedimento para a tutela de interesses coletivos, a ação popular, que posteriormente serviu de inspiração para nossa legislação brasileira.

\subsection{Direitos Coletivos No Brasil}

O Direito Processual Civil foi instituído partindo-se do conjunto de tutelas de conhecimento, execução e cautelar. Todavia, este sistema foi criado para a defesa de interesses individuais, por meio de demandas requeridas pelo próprio prejudicado, não estando previsto qualquer instituto ou instrumento adequado para a tutela de interesses coletivos, a não ser o litisconsórcio ativo, mesmo assim, possuindo este um número limite para que não haja o comprometimento da rápida solução do litígio bem como a defesa do requerido.

Desta forma, não havia previsão para a defesa de interesses transindividuais. Contudo, com o decorrer do tempo, foram surgindo institutos capazes de promover a defesa dos interesses coletivos.

A Lei de Ação Popular no. 4717/1965, desde sua origem atua no sentido de proteger o cidadão e dar-Ihe legitimidade para tutelar interesses coletivos.

Contudo, a Lei de Ação Popular, sofreu grande alteração com a Lei no.

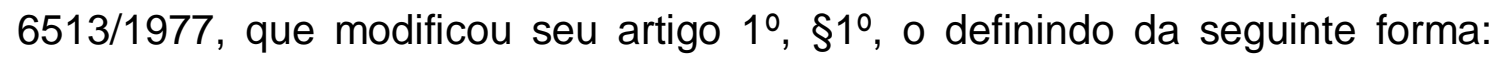
"Consideram-se patrimônio público para os fins referidos neste artigo, os bens e direitos de valor econômico, artístico, estético, histórico ou turístico".

Este foi o primeiro avanço para que a tutela de interesses coletivos fosse concretizada.

Porém, a proteção dos interesses coletivos teve seu principal marco histórico com a Lei no. 7347/1985, conhecida como Lei da Ação Civil Pública. Surgindo aí, os instrumentos processuais que buscam a defesa dos interesses difusos e coletivos.

Com o surgimento da Constituição Federal de 1988 é que foram realmente inaugurados os direitos coletivos, tendo em vista ter sido nela inseridos o direito ao meio ambiente sadio, em seu artigo 225, que diz: "Todos têm direito ao meio ambiente ecologicamente equilibrado, bem de uso comum 
do povo e essencial à sadia qualidade de vida, impondo-se ao Poder Público e à coletividade o dever de defendê-lo e preservá-lo para as presentes e futuras gerações”. O direito à manutenção do patrimônio cultural, no artigo 216, que diz: "Constituem patrimônio cultural brasileiro os bens de natureza material e imaterial, tomados individualmente ou em conjunto, portadores de referência à identidade, à ação, à memória dos diferentes grupos formadores da sociedade brasileira, nos quais se incluem:

I - as formas de expressão;

II - os modos de criar, fazer e viver;

III - as criações científicas, artísticas e tecnológicas;

IV - as obras, objetos, documentos, edificações e demais espaços destinados às manifestações artístico-culturais;

$\mathrm{V}$ - os conjuntos urbanos e sítios de valor histórico, paisagístico, artístico, arqueológico, paleontológico, ecológico e científico".

O direito à preservação da probidade administrativa no artigo $37, \S 4^{\circ}$, que diz: "Os atos de improbidade administrativa importarão a suspensão dos direitos políticos, a perda da função pública, a indisponibilidade dos bens e 0 ressarcimento ao erário, na forma e gradação previstas em lei, sem prejuízo da ação penal cabível”. E ainda, o direito à proteção do consumidor, no artigo 5ํㅡ, XXXII, que diz: "O Estado promoverá, na forma da lei, a defesa do consumidor".

Após, surgiram modificações no Código de Processo Civil para a devida adequação quanto à defesa dos direitos coletivos, bem como em leis esparsas. Contudo, uma grande inovação ocorreu com o advento do Código de Proteção e Defesa do Consumidor, consagrada na Lei nํ. 8078/90, que designou o procedimento adequado a ser adotado nas relações de consumo, instituindo e distinguindo os interesses transindividuais em difusos, coletivos em sentido estrito e individuais homogêneos.

Conforme ensina Teori Albino Zavascki (2007, p. 38),

"formado todo esse cabedal normativo, não há como deixar de reconhecer, em nosso sistema processual, a existência de um subsistema específico, rico e sofisticado, aparelhado para atender aos conflitos coletivos, característicos da sociedade moderna".

Pois bem, os interesses transindividuais, também conhecidos por interesses coletivos em sentido lato, se encontram entre os interesses públicos 
e entre os interesses privados. Tratando-se de interesses que extrapolam os interesses individuais, mas não aproximam exatamente dos interesses públicos.

Os interesses difusos encontram seu conceito no artigo 81, parágrafo único, inciso I, do Código de Defesa do Consumidor, que diz que são "interesses ou direitos difusos, assim entendidos, para efeitos deste código, os transindividuais, de natureza indivisível, de que sejam titulares pessoas indeterminadas e ligadas por circunstâncias de fato".

Deste modo, os interesses difusos são compostos por pessoas indeterminadas, ou seja, indetermináveis e que não exista vínculo jurídico entre elas.

Hugo Nigro Mazzilli (2011, p. 54) faz, porém, uma advertência quanto

\begin{abstract}
a possibilidade de haver confusão entre os interesses difusos e os interesses públicos, explicando que não são, pois, os interesses difusos mera subespécie de interesse público. Embora em muitos casos possa até coincidir o interesse de um grupo indeterminável de pessoas com o interesse do Estado ou com o interesse da sociedade como um todo (como o interesse ao meio ambiente sadio), a verdade é que nem todos interesses difusos são compartilhados pela coletividade ou comungados pelo Estado [...].
\end{abstract}

Os interesses coletivos encontram respaldo no artigo 81, parágrafo único, inciso II, do Código de Defesa do Consumidor, que diz que são "interesses coletivos, os interesses ou direitos coletivos, assim entendidos, para efeitos deste código, os transindividuais, de natureza indivisível de que seja titular grupo, categoria ou classe de pessoas ligadas entre si ou com a parte contrária por uma relação jurídica base".

Entretanto, há que se enfatizar que a ligação entre os lesados deve ser o mesmo interesse coletivo, ou seja, de uma relação jurídica havida entre ambos.

Já os interesses individuais homogêneos, se caracterizam conforme entendimento do artigo 81, parágrafo único, inciso III, do Código de Defesa do Consumidor como "interesses ou direitos individuais homogêneos, assim entendidos os decorrentes de origem comum".

Assim, os interesses individuais homogêneos são aqueles em que os indivíduos são determináveis ou determinados, que dividam o mesmo fato e os 
prejuízos, ou seja, as pessoas são ligadas por uma relação decorrente de fato comum, em que os danos podem ser determinados e partilháveis.

Para Teori Albino Zavascki (2007, p. 42),

[...] os direitos individuais homogêneos são, simplesmente, direitos subjetivos individuais. A qualificação de homogêneos não altera e nem pode desvirtuar essa sua natureza. É qualificativo utilizado para identificar um conjunto de direitos subjetivos individuais ligados entre si por uma relação de afinidade, de semelhança, de homogeneidade, o que permite a defesa coletiva de todos eles.

Portanto, os interesses individuais homogêneos, são os mesmos direitos que são obtidos por ações individuais comuns, porém sua coletivização se deu a fim de se admitir uma tutela em juízo mais rápida e eficaz, evitando-se ainda, decisões conflitantes.

Mas também, destaca Rodolfo de Camargo Mancuso (2004, p. 28) que "o fato do interesse ser exercido por via individual ou coletiva não altera sua essência. A natureza de um interesse advém da finalidade à qual ele está afetado, e não da forma escolhida para o seu exercício".

Destarte, os embriões congelados, são interesses individuais homogêneos, pois se tratam de interesses individuais, mas que podem ser tutelados de forma coletiva evitando-se decisões controversas.

Desta forma, serão tutelados por meio de ação civil pública, que se encontra disciplinada na Lei ㄲo. 7347/85, em que são legitimados para a interposição da presente ação, bem como de ação cautelar, todos os dispostos no artigo $5^{\underline{a}}$, da referida lei, sendo eles:

I - o Ministério Público;

II - a Defensoria Pública;

III - a União, os Estados, o Distrito Federal e os Municípios;

IV - a autarquia, empresa pública, fundação ou sociedade de economia mista;

$\mathrm{V}$ - a associação que, concomitantemente:

a) esteja constituída há pelo menos 1 (um) ano nos termos da lei civil; b) inclua, entre suas finalidades institucionais, a proteção ao meio ambiente, ao consumidor, à ordem econômica, à livre concorrência ou ao patrimônio artístico, estético, histórico, turístico e paisagístico. 
Entretanto, dentre todos os entes legitimados, no presente artigo iremos tratar somente do Ministério Público, pois é o ente que entendemos ter maior oportunidade de obter legitimidade e interesse no caso em estudo.

\title{
5. A LEGITIMIDADE DO MINISTÉRIO PÚBLICO E O INTERESSE DO ESTADO QUANTO AOS EMBRIÕES CONGELADOS
}

Conforme Sérgio Shimura (2006, p. 46) observa

\begin{abstract}
a ação coletiva pode ter por objeto a defesa de direitos difusos, coletivos e individuais homogêneos, evitando, assim, a proliferação de demandas individuais e o desperdício de tempo, atividade, energia, e, o que é pior, a possibilidade de decisões divergentes para uma mesma situação fática. A demanda coletiva contribui para desobstruir a máquina judiciária, obviando o ajuizamento de milhares de ações individuais, veiculadoras de interesses dispersos e fragmentados na sociedade.
\end{abstract}

Para que haja a efetiva tutela dos direitos, necessário se faz verificar-se primeiramente as condições da ação, analisando se encontram devidamente preenchidos os seus requisitos para a admissão da ação proposta.

\subsection{Legitimidade das Partes e Interesse Processual}

A legitimidade e o interesse estão inseridos no rol das condições da ação, que para Marcus Vinicius Rios Gonçalves (2010, p. 80), "são aquelas necessárias para a própria existência da ação. A sua ausência deve ser conhecida pelo juiz de ofício e a qualquer tempo, implicando a extinção do processo sem resolução de mérito".

Assim, são três as condições da ação, sendo elas, legitimidade das partes, interesse processual e possibilidade jurídica do pedido, devendo todas estar presentes no ato da propositura da ação, ou caso contrário, a demanda será extinta sem a apreciação do mérito.

Contudo, há diferença entre a legitimidade e o interesse no direito processual civil individual e no direito processual coletivo. 
Vejamos primeiramente os conceitos e características preconizados no direito processual civil individual.

A legitimidade das partes é a semelhança entre quem ingressa em juízo e o conflito existente.

Luiz Rodrigues Wambier e Eduardo Talamini (2008, p. 161) elucidam com bastante propriedade o conceito de legitimidade das partes, esclarecendo que

\begin{abstract}
autor e réu devem ser partes legítimas. Isso quer dizer que, quanto ao primeiro, deve haver ligação entre ele e o objeto do direito afirmado em juízo. O autor, para que detenha legitimidade, em princípio deve ser o titular da situação jurídica afirmada em juízo (art. 6을 do CPC). Quanto ao réu, é preciso que exista relação de sujeição diante da pretensão do autor.
\end{abstract}

Marcus Vinicius Rios Gonçalves (2010, p. 83) explica que

\begin{abstract}
"a legitimidade é a relação de pertinência subjetiva entre o conflito trazido a juízo e a qualidade para litigar a respeito dele, como demandante ou demandado. Tem de haver uma correspondência lógica entre a causa posta em discussão e a qualidade para estar em juízo litigando sobre ela".
\end{abstract}

Teresa Arruda Alvim Wambier (2007, p. 57) observa, com propriedade, que "a legitimidade é um liame que se estabelece entre um sujeito, um objeto e um outro sujeito".

Desta forma, este é o tipo clássico de legitimidade, conhecida por legitimidade ordinária, porém existe a legitimidade extraordinária, em que se vai à juízo em nome próprio defender direito alheio, em circunstâncias excepcionais e decorrentes de lei expressa.

Nelson Nery Junior e Rosa Maria de Andrade Nery comentam que

"[...] quando aquele que se afirma titular do direito discutido em juízo é a parte legítima diz-se tratar de legitimação ordinária para a causa; ocorre a legitimação extraordinária, da qual a substituição processual (CPC 6ㅇ) é espécie, quando há descoincidência entre a titularidade do direito material e a legitimação para a causa. [...]". 
Não obstante, Alexandre Freitas Câmara (2008, p. 118), faz uma ressalva quanto à possibilidade de confusão entre a legitimidade extraordinária e a substituição processual, alertando que

não se pode confundir a legitimidade extraordinária com a substituição processual. Esta ocorre quando, em um processo, o legitimado extraordinário atua em nome próprio, na defesa de interesse alheio, sem que o legitimado ordinário atue em conjunto com ele. Assim, por exemplo, se o Ministério Público propõe "ação de investigação de paternidade", atuando em defesa do interesse de um menor, teremos substituição processual. $O$ fenômeno não se caracterizará, porém, se a demanda for ajuizada, em litisconsórcio, pelo MP e pelo menor, legitimado ordinário. Em outros termos, só ocorrerá substituição processual quando alguém estiver em juízo em nome próprio, em lugar do (substituindo) legitimado ordinário.

Depreende-se, com isto, que somente ocorrerá legitimidade extraordinária em casos devidamente especificados em lei e principalmente na defesa de ações coletivas.

O interesse processual se trata da constituição da necessidade de se obter a tutela jurídica desejada pela via do Poder Judiciário, ou seja, o bem desejado deve ser necessário e deve ser obtido somente pelo Poder Judiciário, não havendo outra maneira de se obtê-lo, pois havendo, faltará interesse processual e a ação será extinta sem a apreciação do mérito.

Para Luiz Rodrigues Wambier e Eduardo Talamini (2007, p. 160)

o interesse processual está presente sempre que a parte tenha a necessidade de exercer o direito de ação ( e, consequentemente, instaurar o processo) para alcançar 0 resultado que pretende, relativamente à sua pretensão e, ainda mais, sempre que aquilo que se pede no processo (pedido) seja útil sob o aspecto prático.

Apesar disso, Alexandre Freitas Câmara (2008, p. 119), alerta para mais uma particularidade necessária ao interesse processual, esclarecendo que

não basta, porém, que a ida a juízo seja necessária para que o interesse processual esteja presente. É mister, ainda, que haja o interesse- adequação, ou seja, é preciso que o demandante tenha ido a juízo em busca do provimento adequado para a tutela da posição jurídica de vantagem narrada por ele na petição inicial, valendo-se da via processual adequada. 
Com isso, verifica-se que o interesse processual no processo civil individual é caracterizado pela necessidade do pedido, bem como sua adequação, faltando um dos dois requisitos, faltará interesse ao litigante.

\subsection{Legitimidade das Partes e Interesse Processual no Processo Coletivo}

No Direito Processual Coletivo, as coisas ocorrem de forma um pouco diferente, a legitimidade e o interesse não são tratados da mesma maneira que no processo civil individual. Vejamos.

$\mathrm{Na}$ defesa dos interesses difusos, coletivos e individuais homogêneos, a legitimidade será extraordinária, tendo em vista haver a substituição processual na defesa de todos os lesados.

A legitimidade extraordinária no processo coletivo se dá por razões singulares da defesa de direito alheio, pois se assim não fosse, haveriam muitas decisões contraditórias, bem como muitos lesados não iriam ao Poder Judiciário buscar sua tutela, em razão do valor despendido, entre outros motivos. Isso seria praticamente uma negação ao acesso à justiça, além da grande desonra das sentenças prolatadas.

Quanto ao interesse processual do Ministério Público nas palavras de Hugo Nigro Mazzilli $(2011$, p. 391), "é presumido pela própria norma que the impõe a atribuição. Quando a lei the confere legitimidade para acionar ou intervir é porque lhe presume o interesse".

Assim, o interesse processual restará caracterizado somente pela configuração de o Ministério Público estar cumprindo suas funções institucionais.

\subsection{Legitimidade e Interesse Processual do Ministério Público}

O Ministério Público possui como funções a aplicação de leis, o zelo pelo efetivo respeito dos poderes públicos aos direitos assegurados na Constituição, bem como a defesa do patrimônio público, competindo a ele a defesa dos 
direitos indisponíveis e sociais dos cidadãos, possuindo autonomia institucional e independência funcional, assegurados pela Constituição Federal.

Assim, sua legitimidade ativa para propor ações coletivas é concorrente e disjuntiva face aos demais legitimados previstos nos artigos $5^{\circ}$, da Lei de Ação Civil Pública e 82, do Código de Defesa do Consumidor.

Diz-se concorrente, pois todos os legitimados previstos na Lei de Ação Civil Pública e no Código de Defesa do Consumidor podem tutelar interesses transindividuais.

E disjuntiva, pois os legitimados não necessitam comparecer em juízo em litisconsórcio.

O interesse do Ministério Público, como dito anteriormente é presumido, diferentemente do que ocorre com os demais legitimados, que precisam comprovar o interesse.

No caso em estudo, é de fácil percepção notar a legitimidade e o interesse do Ministério Público, pois, os embriões congelados, tratam-se de interesses individuais homogêneos, podendo ser tutelados via ação civil pública, proposta pelo Promotor de Justiça.

Analisados todos os requisitos para que o Ministério Público ingresse com uma ação coletiva na defesa de interesses difusos, coletivos e individuais homogêneos, podemos verificar, pois, a possibilidade de intervenção quanto aos embriões congelados.

Em Recurso Especial interposto pelo Ministério Público do Rio Grande do Sul em que foi extinto o processo sem resolução do mérito, por entender que o Ministério Público não era parte legítima para propor ação civil pública postulando, em nome próprio, direitos individuais alheios com o fim de garantir tratamento médico urgente ao cidadão, sustentou que entre as suas incumbências, estão a de promover, privativamente, a ação penal pública na forma da lei e a de promover o inquérito civil e a ação civil pública na forma da lei para a proteção, prevenção e reparação dos danos causados ao meio ambiente, ao consumidor, aos bens e direitos de valor artístico, estético, histórico, turístico e paisagístico e a outros interesses difusos, coletivos e individuais indisponíveis e homogêneos. Além disso alega que a Constituição 
Federal deu ao MP a legitimidade para defender a ordem jurídica, o regime democrático e os interesses sociais e individuais indisponíveis.

Ao apreciar o recurso, o ministro Luiz Fux, relator do processo, destacou que "é dever da família, da sociedade e do Estado assegurar à criança o direito à saúde e consequentemente o Ministério Público tem a incumbência de promover a defesa dos interesses individuais indisponíveis, podendo, para tanto, exercer outras atribuições previstas em lei, desde que compatíveis com sua finalidade institucional".

A decisão ainda afirma que "o direito à saúde, insculpido na Constituição Federal é direito indisponível, em função do bem comum maior a proteger, derivado da própria forma impositiva dos preceitos e ordem pública que regulam a matéria". (Resp № 738782 - com informações do STJ e da redação do Espaço Vital).

Em vista do julgado acima exposto, conclui-se, que em casos em que há interesses de embriões congelados, pode sim o Ministério Público intervir, pois haverá casos em que se tratará de interesses individuais homogêneos e mesmo já havendo a Lei de Biossegurança nº . 11.105/2005 há ainda muitas lacunas persistentes em nossa legislação atual.

Nestes casos, o Ministério Público poderá intervir, possuindo legitimidade e interesse processual, pois disciplinado em lei, visando à proteção primordial do princípio da dignidade da pessoa humana, para que não haja excessos, nem abusos quando da realização de pesquisas com embriões congelados.

Como exemplo de casos em que poderá haver a intervenção do Ministério Público, podemos citar a ética na realização de pesquisas embrionárias. Embora haja artigo disciplinado na Lei de Biossegurança não podemos garantir que será cumprida, assim caso ocorra qualquer problema, será o Ministério Público competente, pois poderá haver diversos casos de falta de ética nas pesquisas, ou então, muitos embriões sendo pesquisados. Com isto, poderá haver interesse individual, mas também haverá interesses individuais homogêneos. 
Outro caso clássico, será o de práticas científicas com embriões congelados e a correta utilização do banco de tumores. Pois se não houver limites, o Ministério Público poderá intervir.

Conclui-se desta forma, que se tratando de bioética, e principalmente de embriões congelados, por ser um tema muito atual em nosso cotidiano, e nossa legislação não acompanhar tal avanço, pode o Ministério Público intervir, por meio de ação civil pública, vez se tratar de interesses individuais homogêneos, bastando para isso verificar se possui legitimidade e interesse, o que restará facilmente caracterizado, tratando-se de expressa disposição legal.

\section{CONSIDERAÇÕES FINAIS}

Buscou-se, no presente artigo analisar os institutos processuais pertinentes, bem como esclarecer o leitor a respeito dos interesses difusos, coletivos e individuais homogêneos, discorrendo sobre cada qual, para que não reste dúvida. Analisou-se os institutos da legitimidade e do interesse processual, dispostos no Direito Processual Civil e no Direito Coletivo, especificando suas diferenças, bem como suas características, para que ao final a dúvida inicial fosse devidamente esclarecida.

Assim, por todas as razões ora expostas, podemos concluir que existe a possibilidade, embora pequena, de o Ministério Público intervir na devida utilização e conservação de embriões congelados, tendo em vista se tratar de interesses individuais homogêneos e o mesmo possuir legitimidade e interesse processual nos casos advindos.

\section{REFERÊNCIAS BIBLIOGRÁFICAS}

ALMEIDA, Aline Mignon de. Bioética e biodireito. Rio de Janeiro: Lumen Juris, 2000. p. 7.

BERLINGUER, Giovanni. Questões de Vida: Ética, Ciência, Saúde. São Paulo: Editora Hucitec, 1993. 
DALL'AGNOL, Darlei. Bioética. Rio de Janeiro:Jorge Zahar Editor: 2005.

DINIZ, Maria Helena. Conflito de Normas. 2 ed. São Paulo: Saraiva, 1996. . O Estado Atual do Biodireito. 5 ed. São Paulo: Saraiva, 2008.

FABRIZ, Daury Cesar. Bioética e direitos fundamentais: a bioconstituição como paradigma ao biodireto.Belo Horizonte: Mandamentos, 2003.

FERREIRA, Jussara Suzi Assis Borges Nasser. Bioética e Biodireito.

Disponível em:

<http://www.nhu.ufms.br/Bioetica/Textos/Princ\%C3\%ADpios/BIODIREITO\%20 CONCEITO.pdf>.

FREITAS, Alexandre Câmara. Lições de Direito Processual Civil. 18ª ed. Rio de Janeiro: Lumen Juris, 2008.

GERAIGE NETO, Zaiden. O Princípio da Inafastabilidade do Controle Jurisdicional. São Paulo: Revista dos Tribunais, 2003.

GONÇALVES, Marcus Vinicius Rios. Novo Curso de Direito Processual Civil, volume 1: Teoria Geral e Processo de Conhecimento. São Paulo: Saraiva, 2010.

JUNIOR, Nelson Nery; NERY, Rosa Maria de Andrade. Código de Processo Civil Comentado. 10ª ed. São Paulo: Revista dos Tribunais, 2007.

LEÃO, Emmanuel Carneiro. A Célula Tronco Embrionária na ótica do humano. Daimon Editora, 2012.

LEPARGNEUR, Hubert. Força e Fraqueza dos Princípios da Bioética. Bioética v.4 no 2 - Brasília, Conselho Federal de Medicina, 1996.

MÁDERO, Miguel Carlos. Biodireito Constitucional. Rio de Janeiro: Elsevier, 2010.

MANCUSO, Rodolfo de Camargo. Interesses Difusos. Conceito e Legitimação para Agir. São Paulo: Revista dos Tribunais, 2004.

MAZZILLI, Hugo Nigro. A defesa dos Interesses Difusos em Juízo: Meio Ambiente, Consumidor, Patrimônio Público e outros Interesses. 24a ed. São Paulo: Saraiva, 2011.

PESSINI, Leo; BARCHIFONTAINE, Christian de Paul. Problemas Atuais de Bioética. 8 ed. São Paulo: Centro Universitário São Camilo: Loyola, 2007. 
SARLET, Ingo Wolfgang. Dignidade da Pessoa Humana e Direitos

Fundamentais. Ed. Livraria do Advogado. 2004.

SCHRAMM, Fermin Roland; BRAZ, Marlene. Introdução à Bioética. Disponível em: <http://www.ghente.org/bioetica>.

SEGRE, Marco; COHEN, Claudio. Bioética. Editora da Universidade de São

Paulo. $2^{\underline{a}}$ ed. São Paulo: Editora da Universidade de São Paulo, 1999.

SHIMURA, Sérgio. Tutela Coletiva e sua Efetividade. São Paulo: Editora Método, 2006.

WAMBIER, Luiz Rodrigues; TALAMINI, Eduardo. Curso Avançado de Processo Civil: Teoria Geral do Processo e Processo de Conhecimento, v.1. 10. ed. São Paulo: Revista dos Tribunais, 2008.

WAMBIER, Teresa Arruda Alvim. Nulidades do processo e da sentença. 6 $6^{\underline{a}}$ ed. São Paulo: Revista dos Tribunais, 2007.

ZAVASCKI, Teori Albino. Processo Coletivo: Tutela de Direitos Coletivos e Tutela Coletiva de Direitos. $2^{2}$ ed. São Paulo: Revista dos Tribunais, 2007.

Recebido para publicação: 17/06/2013

Aceito para publicação: 08/07/2013 